\title{
On a class of inverse palindromic eigenvalue problem
}

\author{
Jiao $\mathrm{Xu}^{1}$ and Yongxin Yuan $^{1}$ \\ ${ }^{1}$ Hubei Normal University
}

October 6, 2020

\begin{abstract}
In this paper we first give the general solution of the following inverse palindromic eigenvalue problem (IPEP): Given matrices $\$ \backslash$ Lambda $=\backslash \operatorname{mbox}\{\operatorname{diag}\} \backslash\left\{\backslash\right.$ lambda $_{-}\{1\}, \backslash$ cdots, $\backslash$ lambda_ $\left.\{\mathrm{p}\} \backslash\right\} \backslash$ in $\{\backslash \text { mathbb }\{\mathrm{C}\}\}^{\wedge}\{\mathrm{p} \backslash$ times $\mathrm{p}\} \$, \$ \backslash$ lambda $\{$ i $\} \backslash$ neq $\backslash$ lambda_ $\{\mathrm{j}\} \$$ for $\$ \mathrm{i} \backslash$ neq $\mathrm{j} \$, \$ \mathrm{i}, \mathrm{j}=1, \backslash$ cdots, $\mathrm{p} \$, \$ \mathrm{X}=\left[\mathrm{x}_{-}\{1\}, \backslash \operatorname{cdots}, \mathrm{x}_{-}\{\mathrm{p}\}\right] \backslash \operatorname{in}\{\backslash \operatorname{mathbb}\{\mathrm{C}\}\}^{\wedge}\{\mathrm{n} \backslash \operatorname{times} \mathrm{p}\} \$$ with $\$ \backslash \operatorname{mbox}\{\operatorname{rank}\}(\mathrm{X})=$ $\mathrm{p} \$$, and both $\$ \backslash$ Lambda $\$$ and $\$ \mathrm{X} \$$ are closed under complex conjugation in the sense that $\$ \backslash$ lambda $_{-}\{2 \mathrm{i}\}=\backslash$ bar $\{\backslash \text { lambda }\}_{-}$ $\{2 \mathrm{i}-1\} \backslash$ in $\{\backslash \operatorname{mathbb}\{\mathrm{C}\}\} \$, \$ \mathrm{x}_{-}\{2 \mathrm{i}\}=\backslash \operatorname{bar}\{\mathrm{x}\}_{-}\{2 \mathrm{i}-1\} \backslash$ in $\{\backslash \operatorname{mathbb}\{\mathrm{C}\}\}^{\wedge}\{\mathrm{n}\} \$$ for $\$ \mathrm{i}=1, \backslash$ cdots, $\mathrm{m} \$$, and $\$ \backslash$ lambda $-\{\mathrm{j}\} \backslash$ in $\{\backslash \operatorname{mathbb}\{\mathrm{R}\}\} \$, \$ \mathrm{x}_{-}\{\mathrm{j}\} \backslash$ in $\{\backslash \operatorname{mathbb}\{\mathrm{R}\}\}^{\wedge}\{\mathrm{n}\} \$$ for $\$ \mathrm{j}=2 \mathrm{~m}+1, \backslash$ cdots, $\mathrm{p} \$$, find a matrix $\$ \mathrm{~A} \backslash$ in $\{\backslash \operatorname{mathbb}\{\mathrm{R}\}\}^{\wedge}\{\mathrm{n} \backslash$ times $\mathrm{n}\} \$$ such that $\$ \mathrm{AX}=\mathrm{A}^{\wedge} \backslash$ top $\mathrm{X} \backslash$ Lambda. $\$$ We then consider a best approximation problem (BAP): Given $\$ \backslash$ tilde $\{\mathrm{A}\} \backslash$ in $\{\backslash \operatorname{mathbb}\{\mathrm{R}\}\}^{\wedge}\{\mathrm{n} \backslash$ times $\mathrm{n}\} \$$, find $\$ \backslash$ hat $\{\mathrm{A}\} \backslash$ in $\{\backslash \text { mathcal }\{\mathrm{S}\}\}_{-}\{\mathrm{A}\} \$$ such that $\$ \backslash / \backslash$ hat $\{\mathrm{A}\}-\backslash \operatorname{tilde}\{\mathrm{A}\} \backslash \mid=\backslash \min _{-}\{\{\mathrm{A}\} \backslash$ in $\left\{\backslash\right.$ mathcal $\left.\left.\{\mathrm{S}\}_{-}\{\mathrm{A}\}\right\}\right\} \backslash \mid \mathrm{A}-\backslash$ tilde $\{\mathrm{A}\} \backslash \mid, \$$ where $\$ \backslash \backslash \operatorname{cdot} \backslash \mid \$$ is the Frobenius norm and $\$\{\backslash \operatorname{mathcal}\{\mathrm{S}\}\}_{-}\{\mathrm{A}\} \$$ is the solution set of IPEP. We show that the best approximation solution $\$ \backslash$ hat $\{\mathrm{A}\} \$$ is unique and derive an explicit formula for it.
\end{abstract}

\section{Hosted file}

wileyNJD-AMA.pdf available at https://authorea.com/users/364819/articles/485104-on-a-classof-inverse-palindromic-eigenvalue-problem 